\title{
ANALISIS PRESTASI BELAJAR SISWA PADA MATA PELAJARAN EKONOMI DI SMA PGRI 4 PALEMBANG
}

\author{
Oleh: Apriyanto ${ }^{1}$, Neta Dian Lestari ${ }^{2}$ \\ aprisuci31072017@gmail.com ${ }^{1}$, neta_obyta@yahoo.com ${ }^{2}$ \\ (Program Studi Pendidikan Akuntansi, FKIP Universitas PGRI Palembang)
}

\begin{abstract}
Abstrak-Tujuannya yaitu peneliti menganalisis prestasi belajar siswa XI mata pelajaran ekonomi di SMA PGRI 4 Palembang sebanyak 36 siswa. Metode penelitian yaitu menggunakan deskriftip pendekatan kuantitatif. Populasi pada penelitian ini hanya 36 orang atau kurang dari 100 siswa, maka peneliti menggunakan sampel jenuh. Teknik pengumpulan data dan analisis data pada penelitian ini menggunakan teknik observasi dan dokumentasi. Berdasarkan hasil penelitian yang telah peneliti teliti menunjukan hasil, bahwa pada nilai Ulangan harian kesatu sampai dengan ulangangan harian ketga dimana nilai rata-rata yang diperoleh yaitu sebesar 78,18 pada kriteria BAIK. Sedangkan frekuensi diperoleh sebagak 34 siswa pada kategori BAIK yaitu sebesar 94,34\% dan 2 siswa memperoleh kategori Cukup yaitu dengan persentasi sebesar 5,6\%.
\end{abstract}

Kata Kunci: Prestasi, Belajar

\begin{abstract}
The goal is that the researcher analyzes the learning achievement of XI students in economic subjects at SMA PGRI 4 Palembang, as many as 36 students. The research method is using a descriptive quantitative approach, because the population in this study was only 36 people or less than 100 students, the researchers used a saturated sample. Data collection techniques and data analysis in this study using observation and documentation techniques. Based on the results of research that has been carefully researched, the results show that the value of the first daily test to the third daily test where the average value obtained is equal to 78.18 in the GOOD criteria. While the frequency was obtained by 34 students in the GOOD category that is equal to $94.34 \%$ and 2 students got the Fair category which is a percentage of 5.6\%.
\end{abstract}

Keywords: Achievement, Learning

\section{PENDAHULUAN}

Mendidik merupakan tindakan tegas seseorang untuk mendapatkan kebaikan, sebagai jembatan bagi anak didik untuk mendapatkan hal yang bermanfaat untuk masa depannya. Sekolah adalah tempat bagi kaum yang ingin merubah pengetahuaanya dari yang tidak tahu menjadi tahu, sekolah juga sebagai lembaga formal yang harus di tunjang dengan sarana dan prasarana yang baik, guna menunjang proses pembelajaran peserta didik.

"Belajar mengajar adalah suatu kegiatan yang bernilai edukatif Nilai edukatif mewarnai interaksi yang terjadi antara guru dengan anak 
didik.Interaksi yang bernilai edukatif dikarenakan kegiatan belajar mengajar yang dilakukan, diarahkan untuk mencapai tujuan tertentu yang telah dirumuskan sebelum pengajaran dilakukan. Guru dengan sadar merencanakan kegiatan pengajarannya secara sistematis dengan memanfaatkan segala sesuatunya guna kepentingan pengajaran", (Djamarah dan Zain, 2014:1).

Menurut Hamalik (2014:36), "Belajar adalah merupakan suatu proses suatu kegiatan dan bukan suatu hasil atau tujuan. Belajar bukan hanya mengingat, akan tetapi lebih luas daripada itu, yakni mengalami”.

Belajar adalah merupakan tindakan dan perilaku siswa, maka belajar hanya dialami oleh siswa sendiri.Siswa adalah penentu terjadinya atau tidak terjadinya belajar.Belajar merupakan suatu pengetahuan melalui ketelitian fisik dan mental siswa secara aktif.Peran guru terhadap kondisi dan keadaan siswa. Karena setiap siswa memiliki minat, perhatian, tingkat intelegasi kematangan yang berbeda (Suyono dan Hariyanto, 2017:9).

Menurut Slameto (2010:54) yang mempengaruhi belajar banyak jenisnya, tetapi dapat digolongkan menjadi dua golongan saja, yaitu faktor intern dan faktor ekstern. "Prestasi belajar merupakan suatu masalah yang bersifat perennial dalam sejarah kehidupan manusia, karena sepanjang rentang kehidupannya manusia selalu mengejar prestasi menurut bidang dan kemampuan masing-masing" . (Arifin. 2017:12),

Berdasarkan tanggapan diatas pembelajaran dan prestasi merupakan kegiatan yang sangat erat dan tidak dapat dipisahkan proses bembelajaran akan menghasilkan prestasi baik tidaknya anak ddik. Pembelajaran akan selalu ada dalam kehidupan sehari-hari sebagai pengalaman hidup. Sedangkan Prestasi adalah hasil kahir yang didapat tergantung usaha yang telah di capai.

Prestasi yang dicapai oleh setiap siswa pastilah berbeda-beda, tergantung pada pengalaman yang telah dicapai oleh peserta didik. Banyak faktor yang mempengaruhi prestasi siswa, baik berasal dari internal siswa maupun eksternal siswa. Faktor internal merupakan faktor dari dalam individu semua tergantung pada keingginan individu tersebut perumahan yang terjalain atas keingginan pribadi. Sedangkan factor external yaitu factor yang dipengaruhi dari luar seperti dari sekolah, lingkungan dan lain-lain. Faktor external dari sekolah yaitu berupa sarana dan prasarana .

Menurut Lestari, N, D dan Yusmiono, B,A (2018:42) Kegiatan belajar tidak akan berjalan dengan baik apabila sarana dan prasarana kurang memadai, akibatnya hasil belajar yang diperolah akan rendah, dikarenakan manfaat sarana dan 
prasarana pendidikan sangat
mempengaruhi kelancaran $\begin{array}{r}\text { serta } \\ \text { proses }\end{array}$
keberlangsungan
pembelajaran. Sarana belajar di
sekolah sebagai penunjang proses
pembelajaran terdiri dari ruang
$\begin{aligned} & \text { belajar yang mendukung kegiatan } \\ & \text { pembelajaran (Arifin Zainal, } \\ & \text { 2017:14). }\end{aligned}$

Prestasi belajar tidak dapat dipisahkan dari proses belajar, didalamm proses pembelajaran baik pendidik maupun peserta didik harus memiliki bahan ajar, agar prestasi belajar dapat diarahkan dengan baik. Menurut Lestari, N, D\& Pratiwi, N (2019:243) Based on the fact that compiling and making the teaching materials is one form of optimization of teaching materials, which will be applied by the lecturer in the classroom .

Karena belajar dan prestasi adalah tanggung jawab bukan hanya peserta didik tetapi pendidik dan orang tua. Sebagian seseorang belajar merupakan suatu kewajiban. Untuk mengetahui berhasil atau tidaknya seseorang tersebut dalam pendidikan tergantung pada proses belajar yang dialami oleh peserta didik. Dari hasil data dokumentasi yang peneliti dapatkan berupa nilai ulangan harian dan mid semester (Ganjil) kelas XI di SMA PGRI 4 Palembang nilai KKM pada mata pelajaran ekonomi 70.

Berdasarkan hal tersebut maka peneliti bermaksud mengadakan penelitian dengan judul "Analisis
Prestasi Belajar Siswa Dalam Mata Pelajaran Ekonomi Di SMA PGRI 4 Palembang Tahun Pelajaran 2019/2020".

\section{METODE PENELITIAN}

"Metode penelitian adalah cara yang digunakan oleh peneliti dalam mengumpulkan data penelitian" (Arikunto, 2013:203). Sedangkan menurut Sugiyono (2015:13). Metode penelitian kuantitatif dapat diartikan sebagai metode penelitian yang berlandaskan pada filsafat positivism, digunakan untuk meneliti pada populasi atau sampel tertentu, teknik pengambilan sampel pada umumnya dilakukan secara probability sampling, pengumpulan data menggunakan instrument penelitian, analisis data bersifat kuantitatif/statisik dengan tujuan menguji hipotesis yang telah ditetapkan.

Pada penelitian ini peneliti menggunakan Metode deskriptif dengan pendekatan Kuantitatif. Penepenelitian ini untuk mencapai dan memperoleh sasaran yang tepat dan informasi yang akurat, maka teknik yang digunakan yaitu dokumentasi, wawancara dan observasi. Berikut ini akan dijelaskan satu persatu

"Dokumentasi adalah mencari data mengenai hal-hal atau variabel yang berupa catatan, transaksi, buku, surat kabar, majalah, prasasti, notulen, rapat, lengger, agenda" (Arikunto, 2013:274).Dokumentasi 
dalam penelitian ini digunakan untuk mengetahui atau mendapatkan data berupa nilai mid serta raport, jumlah siswa, jumlah guru dan keadaan guru di SMA PGRI 4 Palembang tahun ajaran 2019/2020.

"Statistik deskriptif adalah statistik yang digunakan untuk menganalisis data dengan cara mendeskripsikan atau menggambarkan data yang telah terkumpul sebagaiman adanya tanpa bermaksud membuat kesimpulan yang berlaku untuk umum atau generalisasi" (Sugiyono, 2015:207). Langkah-langkah penenelitian yaitu sebgai berikut:

1. Peneliti menilai hasil tes yang peneliti dapatkan dari Guru mata pelajaran ekonomi, kemudian mengolahnya dengan cara mengubah skor menjadi nilai standar

$$
S=\frac{B}{N} \times 100
$$

2. Menghitung frekuensi persentase siswa pada tiap indikator dengan menggunakan rumus

$$
\mathrm{P}=\frac{f}{n} x 100 \%
$$

(Haryadi, 2009:24)
3. Menghitung rata-rata pemahaman siswa dengan menggunakan:

persamaan:

$$
\text { rata }- \text { rata }=\frac{\text { totalnilai }}{\text { juml ahsampel }}
$$

Tabel 1. Kategori Penilaian Hasil

\section{Belajar}

\begin{tabular}{|c|c|c|}
\hline No & Nilai & Keterangan \\
\hline 1 & $86-100$ & Baik sekali \\
\hline 2 & $71-85$ & Baik \\
\hline 3 & $56-70$ & Cukup \\
\hline 4 & $41-55$ & Kurang \\
\hline 5 & $<40$ & $\begin{array}{c}\text { Kurang } \\
\text { Sekali }\end{array}$ \\
\hline
\end{tabular}

(Sumber : Depdiknas, 2012:34)

HASIL DAN PEMBAHASAN

Deskripsi Data Hasil Belajar Siswa 
Tabel 2. Daftar Nilai Ulangan Harian 1 (Siswa Kelas XI IPS1) SMA PGRI 4 Palembang Tahun Ajaran 2019-2020

\begin{tabular}{|c|c|c|c|c|c|}
\hline No & Nama Siswa & $\mathbf{L} / \mathbf{P}$ & Kog & Afek & Keterangan \\
\hline 1 & Abdi Abdullah Putra & $\mathrm{L}$ & 70 & $\mathrm{~B}$ & Tuntas \\
\hline 2 & Agus Said & $\mathrm{L}$ & 73 & B & Tuntas \\
\hline 3 & Ahmad Aldi & $\mathrm{L}$ & 80 & A & Tuntas \\
\hline 4 & Alfi Khoiron & $\mathrm{L}$ & 71 & B & Tuntas \\
\hline 5 & Alfina & $\mathrm{P}$ & 71 & B & Tuntas \\
\hline 6 & Andre Ardana & $\mathrm{L}$ & 80 & A & Tuntas \\
\hline 7 & Ardiansyah & $\mathrm{L}$ & 68 & B & Tuntas \\
\hline 8 & Arisma Sandi & $\mathrm{L}$ & 78 & B & Tuntas \\
\hline 9 & Cindy & $\mathrm{P}$ & 78 & B & Tuntas \\
\hline 10 & Dea Viona Irawan & $\mathrm{P}$ & 78 & B & Tuntas \\
\hline 11 & Demitri Alfiano Aditia Renaldi & $\mathrm{L}$ & 76 & B & Tuntas \\
\hline 12 & Dian Putra & $\mathrm{L}$ & 78 & B & Tuntas \\
\hline 13 & Erwin Saputra & $\mathrm{L}$ & 77 & B & Tuntas \\
\hline 14 & Feby Lestari & $\mathrm{P}$ & 80 & B & Tuntas \\
\hline 15 & Icha Anggita Putri & $\mathrm{P}$ & 80 & B & Tuntas \\
\hline 16 & Irvan Wahyuda & $\mathrm{L}$ & 78 & B & Tuntas \\
\hline 17 & Listya Syakila & $\mathrm{L}$ & 75 & B & Tuntas \\
\hline 18 & Mahesa & $\mathrm{L}$ & 70 & B & Tuntas \\
\hline 19 & Mgs. Taufik Akbar & $\mathrm{L}$ & 70 & B & Tuntas \\
\hline 20 & Muhammad Ridho & $\mathrm{L}$ & 70 & B & Tuntas \\
\hline 21 & Nur Annisyah & $\mathrm{P}$ & 72 & B & Tuntas \\
\hline 22 & Okta Diana & $\mathrm{P}$ & 80 & A & Tuntas \\
\hline 23 & Ferdi & $\mathrm{L}$ & 78 & B & Tuntas \\
\hline 24 & Putri Melisa & $\mathrm{P}$ & 80 & A & Tuntas \\
\hline 25 & Restu Fajar & $\mathrm{L}$ & 71 & B & Tuntas \\
\hline 26 & Riski Nur Hidayat & $\mathrm{L}$ & 77 & B & Tuntas \\
\hline 27 & Rizki Juliono & $\mathrm{L}$ & 75 & B & Tuntas \\
\hline 28 & Sahrul Guawan & $\mathrm{L}$ & 70 & B & Tuntas \\
\hline 29 & Sania Salsabilla & $\mathrm{P}$ & 72 & B & Tuntas \\
\hline 30 & Septi Anggraini & $\mathrm{P}$ & 78 & B & Tuntas \\
\hline 31 & Siti Munawaroh Oktaria & $\mathrm{P}$ & 80 & A & Tuntas \\
\hline 32 & Siti Qomariah & $\mathrm{P}$ & 78 & B & Tuntas \\
\hline 33 & Tiara Raihan Fatin & $\mathrm{P}$ & 70 & B & Tuntas \\
\hline 34 & Tri Prayoga & $\mathrm{P}$ & 70 & B & Tuntas \\
\hline 35 & Trivaldo Frandesta Wijaya & $\mathrm{L}$ & 80 & B & Tuntas \\
\hline 36 & Debby Marten & $\mathrm{L}$ & 75 & $\mathrm{~B}$ & Tuntas \\
\hline \multicolumn{2}{|r|}{ Jumlah } & & 2707 & & \\
\hline \multicolumn{2}{|r|}{ Rata-rata } & & 75,19 & & \\
\hline
\end{tabular}

Sumber: SMA 4 PGRI Palembang, 2020 
Berdasarkan uraian tabel di atas diketahui bahwa siswa kelas XI. IPS 1 SMA Negeri 4 Palembang pada ulangan harian kesatu diperoleh nilai rata rata siswa sebesar 75.19 , ini menunjukkan bahwa pada ulangan harian 1 siswa XI.IPS 1 tergolong memiliki prestasi baik. dengan perhitungan:

$$
\begin{aligned}
& s \frac{B}{n} \times 100 \\
& s \frac{2702}{36} \times 100 \\
& s=75,19
\end{aligned}
$$

Tabel 3.Distribusi Frekuensi Ulangan Harian 1 (Siswa Kelas XI.IPS1) SMA PGRI 4 Palembang Tahun Ajaran 2019-2020

\begin{tabular}{|c|c|c|c|c|}
\hline No & Nilai & Frekuensi & Presentasi & Keterangan \\
\hline 1 & $86-100$ & 0 & 0,0 & Baik sekali \\
2 & $71-85$ & 27 & 75,0 & Baik \\
3 & $56-70$ & 9 & 25,0 & Cukup \\
4 & $41-55$ & 0 & 0,0 & Kurang \\
5 & $<40$ & 0 & 0,0 & Kurang Sekali \\
\hline \multicolumn{2}{|c|}{ Jumlah } & $\mathbf{3 6}$ & $\mathbf{1 0 0}$ & \\
\hline
\end{tabular}

Sumber: SMA 4 PGRI Palembang, 2020

Berdasarkan uraian diatas frekuensi terbesar yaitu pada nilai 71 sampai dengan 85 sebanyak 27 siswa dengan persentasi $75 \%$ pada kategori Baik.

\begin{tabular}{|c|c|c|c|c|c|}
\hline No & Nama Siswa & $\mathbf{L} / \mathbf{P}$ & Kog & Afek & Keterangan \\
\hline 1 & Abdi Abdullah Putra & $\overline{\mathrm{L}}$ & 73 & $\overline{\mathrm{B}}$ & Tuntas \\
\hline 2 & Agus Said & $\mathrm{L}$ & 75 & B & Tuntas \\
\hline 3 & Ahmad Aldi & $\mathrm{L}$ & 83 & A & Tuntas \\
\hline 4 & Alfi Khoiron & $\mathrm{L}$ & 75 & B & Tuntas \\
\hline 5 & Alfina & $\mathrm{P}$ & 75 & B & Tuntas \\
\hline 6 & Andre Ardana & $\mathrm{L}$ & 85 & A & Tuntas \\
\hline 7 & Ardiansyah & $\mathrm{L}$ & 70 & B & Tuntas \\
\hline 8 & Arisma Sandi & $\mathrm{L}$ & 80 & B & Tuntas \\
\hline 9 & Cindy & $\mathrm{P}$ & 80 & B & Tuntas \\
\hline 10 & Dea Viona Irawan & $\mathrm{P}$ & 80 & B & Tuntas \\
\hline 11 & Demitri Alfiano Aditia Renaldi & $\mathrm{L}$ & 80 & B & Tuntas \\
\hline 12 & Dian Putra & $\mathrm{L}$ & 80 & B & Tuntas \\
\hline 13 & Erwin Saputra & $\mathrm{L}$ & 80 & B & Tuntas \\
\hline 14 & Feby Lestari & $\mathrm{P}$ & 82 & B & Tuntas \\
\hline 15 & Icha Anggita Putri & $\mathrm{P}$ & 82 & B & Tuntas \\
\hline
\end{tabular}

Tabel 4.Daftar Nilai Ulangan Harian 2 Siswa Kelas XI.IPS1) SMA PGRI 4 Palembang Tahun Ajaran 2019-2020 


\begin{tabular}{|c|c|c|c|c|c|}
\hline 16 & Irvan Wahyuda & $\mathrm{L}$ & 80 & $\mathrm{~B}$ & Tuntas \\
\hline 17 & Listya Syakila & $\mathrm{L}$ & 82 & B & Tuntas \\
\hline 18 & Mahesa & $\mathrm{L}$ & 70 & $\mathrm{C}$ & Tuntas \\
\hline 19 & Mgs. Taufik Akbar & $\mathrm{L}$ & 70 & $\mathrm{C}$ & Tuntas \\
\hline 20 & Muhammad Ridho & $\mathrm{L}$ & 70 & $\mathrm{C}$ & Tuntas \\
\hline 21 & Nur Annisyah & $\mathrm{P}$ & 81 & $\mathrm{~B}$ & Tuntas \\
\hline 22 & Okta Diana & $\mathrm{P}$ & 83 & A & Tuntas \\
\hline 23 & Ferdi & $\mathrm{L}$ & 80 & $\mathrm{~B}$ & Tuntas \\
\hline 24 & Putri Melisa & $\mathrm{P}$ & 82 & $\mathrm{~B}$ & Tuntas \\
\hline 25 & Restu Fajar & $\mathrm{L}$ & 78 & $\mathrm{~B}$ & Tuntas \\
\hline 26 & Riski Nur Hidayat & $\mathrm{L}$ & 80 & $\mathrm{~B}$ & Tuntas \\
\hline 27 & Rizki Juliono & $\mathrm{L}$ & 78 & $\mathrm{~B}$ & Tuntas \\
\hline 28 & Sahrul Guawan & $\mathrm{L}$ & 75 & B & Tuntas \\
\hline 29 & Sania Salsabilla & $\mathrm{P}$ & 75 & $\mathrm{~B}$ & Tuntas \\
\hline 30 & Septi Anggraini & $\mathrm{P}$ & 80 & $\mathrm{~B}$ & Tuntas \\
\hline 31 & Siti Munawaroh Oktaria & $\mathrm{P}$ & 83 & A & Tuntas \\
\hline 32 & Siti Qomariah & $\mathrm{P}$ & 80 & $\mathrm{~B}$ & Tuntas \\
\hline 33 & Tiara Raihan Fatin & $\mathrm{P}$ & 75 & $\mathrm{~B}$ & Tuntas \\
\hline 34 & Tri Prayoga & $\mathrm{P}$ & 75 & $\mathrm{C}$ & Tuntas \\
\hline 35 & Trivaldo Frandesta Wijaya & $\mathrm{L}$ & 83 & $\mathrm{~B}$ & Tuntas \\
\hline 36 & Debby Marten & $\mathrm{L}$ & 78 & $\mathrm{~B}$ & Tuntas \\
\hline \multicolumn{3}{|c|}{ Jumlah } & 2818 & & \\
\hline \multicolumn{3}{|c|}{ Rata-Rata } & 78,28 & & \\
\hline
\end{tabular}

Sumber: SMA 4 PGRI Palembang, 2020

Berdasarkan uraian tabel di atas diketahui bahwa siswa kelas XI. IPS 1 SMA Negeri 4 Palembang pada ulangan harian kesatu diperoleh nilai rata rata siswa sebesar 78.28 , ini menunjukkan bahwa pada ulangan harian kedua siswa XI.IPS 1 tergolong memiliki prestasi baik. dengan perhitungan :

$$
\begin{aligned}
& s=\frac{B}{n} x 100 \\
& s=\frac{2818}{36} \times 100 \\
& s=78,28
\end{aligned}
$$

Tabel 5.Distribusi Frekuensi Ulangan Harian 2 (Siswa Kelas XI.IPS1) SMA PGRI 4 Palembang Tahun Ajaran 2019-2020

\begin{tabular}{|c|c|c|c|c|}
\hline No & Nilai & Frekuensi & Presentasi & Keterangan \\
\hline 1 & $86-100$ & 0 & 0,00 & Baik sekali \\
\hline 2 & $71-85$ & 32 & 88,89 & Baik \\
\hline 3 & $56-70$ & 4 & 11,11 & Cukup \\
\hline 4 & $41-55$ & 0 & 0,00 & Kurang \\
\hline 5 & $<40$ & 0 & 0,00 & Kurang Sekali \\
\hline \multicolumn{2}{|r|}{ Jumlah } & 36 & 100,00 & \\
\hline
\end{tabular}

Sumber: Diolah dari Hasil Penelitian 2020 
Berdasarkan uraian diatas dengan persentasi $88,89 \%$ pada frekuensi terbesar yaitu pada nilai 71 kategori Baik.

sampai dengan 85 sebanyak 32 siswa

Tabel 6.Daftar Nilai Ulangan Harian 3 (Siswa Kelas XI IPS1) SMA PGRI 4 Palembang Tahun Ajaran 2019-2020

\begin{tabular}{|c|l|c|c|c|c|}
\hline No & \multicolumn{1}{|c|}{ Nama Siswa } & L/P & Kog & Afek & Keterangan \\
\hline 1 & Abdi Abdullah Putra & L & 76 & B & Tuntas \\
2 & Agus Said & L & 76 & B & Tuntas \\
3 & Ahmad Aldi & L & 87 & A & Tuntas \\
4 & Alfi Khoiron & L & 80 & B & Tuntas \\
5 & Alfina & P & 80 & B & Tuntas \\
6 & Andre Ardana & L & 87 & A & Tuntas \\
7 & Ardiansyah & L & 83 & B & Tuntas \\
8 & Arisma Sandi & P & 83 & B & Tuntas \\
9 & Cindy & P & 85 & B & Tuntas \\
10 & Dea Viona Irawan & L & 81 & B & Tuntas \\
11 & Demitri Alfiano Aditia Renaldi & L & 81 & B & Tuntas \\
12 & Dian Putra & L & 81 & B & Tuntas \\
13 & Erwin Saputra & P & 85 & B & Tuntas \\
14 & Feby Lestari & P & 85 & B & Tuntas \\
15 & Icha Anggita Putri & L & 82 & B & Tuntas \\
16 & Irvan Wahyuda & L & 82 & B & Tuntas \\
17 & Listya Syakila & L & 72 & B & Tuntas \\
18 & Mahesa & L & 71 & B & Tuntas \\
19 & Mgs. Taufik Akbar & L & 75 & B & Tuntas \\
20 & Muhammad Ridho & P & 85 & B & Tuntas \\
21 & Nur Annisyah & P & 86 & A & Tuntas \\
22 & Okta Diana & L & 82 & B & Tuntas \\
23 & Ferdi & P & 85 & B & Tuntas \\
24 & Putri Melisa & L & 80 & B & Tuntas \\
25 & Restu Fajar & L & 82 & B & Tuntas \\
26 & Riski Nur Hidayat & L & 80 & B & Tuntas \\
27 & Rizki Juliono & L & 78 & B & Tuntas \\
28 & Sahrul Guawan & P & 78 & B & Tuntas \\
29 & Sania Salsabilla & P & 82 & B & Tuntas \\
30 & Septi Anggraini & P & 85 & A & Tuntas \\
31 & Siti Munawaroh Oktaria & P & 82 & B & Tuntas \\
32 & Siti Qomariah & P & 80 & B & Tuntas \\
33 & Tiara Raihan Fatin & P & 80 & B & Tuntas \\
34 & Tri Prayoga & L & 86 & B & Tuntas \\
35 & Trivaldo Frandesta Wijaya & L & 80 & B & Tuntas \\
36 & Debby Marten & & $\mathbf{2 9 1 8}$ & & \\
\hline & & $\mathbf{8 1 , 0 6}$ & & \\
\hline & & & & \\
\hline
\end{tabular}

Sumber: SMA 4 PGRI Palembang, 2020

Berdasarkan uraian tabel di IPS 1 SMA Negeri 4 Palembang atas diketahui bahwa siswa kelas XI. pada ulangan harian kesatu diperoleh 
nilai rata rata siswa sebesar 81,06 , ini menunjukkan bahwa pada

$$
\begin{aligned}
& s=\frac{B}{n} \times 100 \\
& s=\frac{2918}{36} \times 100 \\
& s=81,06
\end{aligned}
$$

Tabel 7. Distribusi Frekuensi Ulangan Harian 3 (Siswa Kelas XI.IPS1) SMA PGRI 4 Palembang Tahun Ajaran 2019-2020

\begin{tabular}{|c|c|c|c|c|}
\hline No & Nilai & Frekuensi & Presentasi & Keterangan \\
\hline 1 & $86-100$ & 0 & 0 & Baik sekali \\
\hline 2 & $71-85$ & 36 & 100 & Baik \\
\hline 3 & $56-70$ & 0 & 0 & Cukup \\
\hline 4 & $41-55$ & 0 & 0 & Kurang \\
\hline 5 & $<40$ & 0 & 0 & Kurang Sekali \\
\hline Jumlah & & 36 & 100 & \\
\hline Rata-rata & & & & \\
\hline
\end{tabular}

Sumber: Diolah dari Hasil Penelitian 2020

Berdasarkan uraian diatas frekuensi terbesar yaitu pada nilai 71 sampai dengan 85 sebanyak 36 siswa dengan persentasi $100 \%$ pada kategori Baik

Tabel 8. Daftar Rekapitulasi Nilai Ulangan Harian (Siswa Kelas XI IPS1) SMA PGRI 4 Palembang Tahun Ajaran 2019-2020

\begin{tabular}{|c|l|c|c|c|c|c|c|}
\hline No & \multicolumn{1}{|c|}{ Nama Siswa } & UH 1 & UH 2 & UH 3 & Jumlah & $\begin{array}{c}\text { Rata-Rata } \\
\text { UH }\end{array}$ & Keterangan \\
\hline 1 & Abdi Abdullah Putra & 70 & 73 & 76 & 219 & 73 & Tuntas \\
2 & Agus Said & 73 & 75 & 76 & 224 & 75 & Tuntas \\
3 & Ahmad Aldi & 80 & 83 & 87 & 250 & 83 & Tuntas \\
4 & Alfi Khoiron & 70 & 75 & 80 & 225 & 75 & Tuntas \\
5 & Alfina & 72 & 75 & 80 & 227 & 76 & Tuntas \\
6 & Andre Ardana & 80 & 85 & 87 & 252 & 84 & Tuntas \\
7 & Ardiansyah & 68 & 70 & 75 & 213 & 71 & Tuntas \\
8 & Arisma Sandi & 78 & 80 & 83 & 241 & 80 & Tuntas \\
9 & Cindy & 78 & 80 & 83 & 241 & 80 & Tuntas \\
10 & Dea Viona Irawan & 78 & 80 & 85 & 243 & 81 & Tuntas \\
11 & Demitri Alfiano Aditia R & 76 & 80 & 81 & 237 & 79 & Tuntas \\
12 & Dian Putra & 78 & 80 & 81 & 239 & 80 & Tuntas \\
13 & Erwin Saputra & 77 & 80 & 81 & 238 & 79 & Tuntas \\
14 & Feby Lestari & 80 & 82 & 85 & 247 & 82 & Tuntas \\
15 & Icha Anggita Putri & 80 & 82 & 85 & 247 & 82 & Tuntas \\
16 & Irvan Wahyuda & 78 & 80 & 82 & 240 & 80 & Tuntas \\
17 & Listya Syakila & 75 & 82 & 82 & 239 & 80 & Tuntas \\
\hline
\end{tabular}




\begin{tabular}{|l|l|c|c|c|c|c|c|}
\hline 18 & Mahesa & 70 & 70 & 72 & 210 & 70 & Tuntas \\
19 & Mgs. Taufik Akbar & 70 & 70 & 71 & 209 & 70 & Tuntas \\
20 & Muhammad Ridho & 70 & 70 & 75 & 213 & 71 & Tuntas \\
21 & Nur Annisyah & 72 & 81 & 85 & 244 & 81 & Tuntas \\
22 & Okta Diana & 80 & 83 & 86 & 249 & 83 & Tuntas \\
23 & Ferdi & 78 & 80 & 82 & 240 & 80 & Tuntas \\
24 & Putri Melisa & 80 & 82 & 85 & 247 & 82 & Tuntas \\
25 & Restu Fajar & 71 & 78 & 80 & 229 & 76 & Tuntas \\
26 & Riski Nur Hidayat & 77 & 80 & 82 & 239 & 80 & Tuntas \\
27 & Rizki Juliono & 75 & 78 & 80 & 233 & 78 & Tuntas \\
28 & Sahrul Guawan & 70 & 75 & 78 & 223 & 74 & Tuntas \\
29 & Sania Salsabilla & 72 & 75 & 78 & 225 & 75 & Tuntas \\
30 & Septi Anggraini & 78 & 80 & 82 & 240 & 80 & Tuntas \\
31 & Siti Munawaroh & 80 & 83 & 85 & 248 & 83 & Tuntas \\
& Oktaria & & & & & & \\
32 & Siti Qomariah & 78 & 80 & 82 & 240 & 80 & Tuntas \\
33 & Tiara Raihan Fatin & 70 & 75 & 80 & 225 & 75 & Tuntas \\
34 & Tri Prayoga & 70 & 75 & 80 & 225 & 75 & Tuntas \\
35 & Trivaldo Frandesta & 80 & 83 & 86 & 249 & 83 & Tuntas \\
& Wijaya & & & & & & \\
36 & Debby Marten & 75 & 78 & 80 & 233 & 78 & Tuntas \\
\hline \multicolumn{2}{|c|}{ Jumlah } & $\mathbf{2 7 0 7}$ & $\mathbf{2 8 1 8}$ & $\mathbf{2 9 1 8}$ & $\mathbf{8 4 4 3}$ & $\mathbf{2 8 1 4 , 3 3}$ & \\
\hline & Rata-Rata & $\mathbf{7 5 , 1 9}$ & $\mathbf{7 8 , 2 8}$ & $\mathbf{8 1 , 0 6}$ & $\mathbf{2 3 4 , 5 3}$ & $\mathbf{7 8 , 1 8}$ & \\
\hline
\end{tabular}

Sumber: SMA 4 PGRI Palembang, 2020

Tabel 9.Distribusi Frekuensi Hasil Belajar Siswa dari ulangan ke 1 sampai ke 3 (Siswa Kelas XI IPS1) SMA PGRI 4 Palembang Tahun Ajaran 2019-2020

\begin{tabular}{|c|c|c|c|c|}
\hline No & Nilai & Frekuensi & Presentasi & Keterangan \\
\hline 1 & $86-100$ & 0 & 0,0 & Baik sekali \\
\hline 2 & $71-85$ & 34 & 94,4 & Baik \\
\hline 3 & $56-70$ & 2 & 5,6 & Cukup \\
\hline 4 & $41-55$ & 0 & 0,0 & Kurang \\
\hline 5 & $<40$ & 0 & 0,0 & Kurang Sekali \\
\hline Jumlah & & 36 & 100 & \\
\hline Rata-rata & & & & \\
\hline
\end{tabular}

Sumber: Diolah dari Hasil Penelitian 2020

Berdasarkan tabel rekapitulasi tabel frekuensi diatas nilai terbesar yaitu pada nilai 71 sampai dengan 85 sebanyak 34 siswa pada kategori Baik dengan persentasi $94,4 \%$ dan 2 siswa dalam kategori cukup pada persentasi sebesar 5.6\%. Berarti siswa dengan predikat kurang dan kurang sekali yaitu 0 siswa dengan persentase $0,0 \%$. 


\section{KESIMPULAN}

Berdasarkan pembahasan yang peneliti lakukan dengan judul "Analisis Prestasi Belajar Siswa dalam Mata Pelajaran Ekonomi di SMA PGRI 4 Palembang Tahun Pelajaran 2019/2020". Dari hal tersebut dapat disimpulkan nilai ratarata dari nilai ulangan harian pertama sampai ketiga yaitu sebesar 78,18 pada kriteria baik. Sedangkan frekuensi diperoleh persentase sebesar 94,34\% yaitu sebanyak 34 siswa dan 2 siswa pada kategori cukup atau sebesar 5,6\% .

\section{DAFTAR PUSTAKA}

Arifin Zainal. (2017). Metode Penelitian Pendidikan. Bandung: Alfabeta.

Arikunto, Suharsimi. (2013). Prosedur Penelitian. Jakarta: PT Asdi Mahasatya.

Djamarah, Syaiful Bahri dan Aswan Zain. (2014). Strategi Belajar Mengajar. Jakarta: Rineka Cipta.

Hamalik, Oemar. (2011). Kurikulum dan Pembelajaran. Jakarta: Bumi Aksara

Lestari, N. D., \& Yusmiono, B. A. (2018). Analisis Penggunaan Sarana dan Prasarana untuk Menunjang Kegiatan Belajar Mahasiswa di Universitas PGRI Palembang Tahun Akademik 2016/2017. JMKSP (Jurnal Manajemen, Kepemimpinan, dan Supervisi Pendidikan), 3(1). https://jurnal.univpgripalembang.ac.id/index.php/JM KSP/article/view/1522/1327 Lestari, N. D., \& Pratiwi, N. (2019). Optimization Of Entreprenership Materials To Increase The Students' Learning Result Accounting Education Study Programs University PGRI Of Palembang. International Journal of Scientific \& Technology Research (IJSTR). April 2019 ISSN 2277-8616. 8/4.Url

https://www.ijstr.org/finalprint/apr2019/OptimizationOf-Entreprenership-MaterialsTo-Increase-The-StudentsLearning-Result-AccountingEducation-Study-ProgramsUniversity-Pgri-OfPalembang.pdf Slameto. (2010). Belajar dan Faktor yang mempengaruhinya. Jakarta: Rineka Cipta.

Sugiyono. (2012). Statistika Untuk Penelitian. Bandung: Alfabeta. Suyono dan Hariyanto. (2017). Belajar dan Pembelajaran. Bandung: PT. Remaja Rosdakarya. 